\title{
KEMUNDURAN DAN KERUNTUHAN DAULAH BANI UMAWIYAH DI DAMASKUS DAN ANDALUSIA (STUDI PUSTAKA)
}

\author{
LATIFA ANNUM DALIMUNTHE \\ Dosen Sekolah Tinggi Agama Islam Negeri Palangkaraya
}

\begin{abstract}
Year $41 \mathrm{H}$ (661), began the Umayyad rule in the history of the children of political Islam in Damaskus. The development of civilization covering the fields of architecture, military organizations, trade and fiscal reforms. Then suffered a setback that eventually collapse due to, among others, (1). The weakness of the khafilah. (2). The emergence of inter-group conflict. The emergence of inter-group conflict. The direct causes of the overthrow of the emergence of new powers, spearheaded by the descendants of al-Abbas ibn Abd al-Muttalib, this movement is supported by the Bani Hashim and the Shiite group of people who feel dikelasduakan mawali by Bani Umayyad rule.

On May 14, 756, Kardova successfully conquered by Abdur Rahman and his followers. In a period of more than seven centuries of Muslim rule in Andalusia (Spain) achieve glory. in the field of intellectual progress: philosophy, science, jurisprudence, music and performing arts, language and literature. Then the physical development among others in Cordova (capital of Spain), trees and flowers imported from the east, there are 491 mosques, 900 baths, establish drainage from the mountains of length $80 \mathrm{~km}$ ) while Granada is Al-Hamra palace, palace of al-Gajar, tower Girilda. Progress achieved daulah sons Umayyad West (Andalusia), decline and eventually collapse. The deterioration factor to cause the collapse, among others: (1). Lack of clarity about the transition of power systems. (2) Economic Difficulty. (3). The absence of a unifying ideology. (4) Islamic conflict with Christianity.
\end{abstract}

Key words: setbacks, collapse, Bani Umawiyyah daula, Damaskus, Spain

\begin{abstract}
ABSTRAK
Tahun $41 \mathrm{H}$ (661), dimulailah kekuasaan bani Umawiyah dalam sejarah politik Islam di Damaskus. Adapun perkembangan peradapan meliputi bidang arsitektur, organisasi militer, perdagangan dan reformasi fiscal. Kemudian mengalami kemunduran yang pada akhirnya mengalami keruntuhan disebabkan antara lain (1). Lemahnya para khafilah. (2). Munculnya konflik antar golongan. Penyebab langsung tergulingnya munculnya kekuatan baru yang dipelopori oleh keturunan Al-Abbas ibn Abd Al-Muthalib, gerakan ini didukung oleh Bani Hasyim dan golongan Syi'ah dari kaum mawali yang merasa dikelasduakan oleh pemerintahan Bani Umawiyah.

Pada tanggal 14 Mei 756, Kardova berhasil ditaklukkan oleh Abdur Rahman dan pengikutnya. Dalam masa lebih dari 7 abad kekuasaan Islam di Andalusia (Spanyol) mencapai kejayaannya dalam bidang kemajuan intelektual : filsafat, sains, fikih, musik dan keseniaan, bahasa dan sastra. Kemudian pembangunan fisik antara lain di Cordova (Ibukota Spanyol), pohon-pohon dan bunga-bunga di impor dari timur, terdapat 491 masjid, 900 tempat pemandian, mendirikan saluran air dari pegunungan panjangnya 80 km) sedangkan di Granada adalah Istana Al-Hamra, istana al-Gajar, menara Girilda. Kemajuan yang dicapai daulah bani Umawiyah Barat (Andalusia), pada akhirnya mengalami kemunduran dan keruntuhan. Adapun faktor kemunduran hingga menyebabkan keruntuhan antara lain: (1). Tidak jelasnya sistem peralihan kekuasaan. (2) Kesulitan Ekonomi. (3). Tidak adanya ideologi pemersatu. (4) terjadinya konflik Islam dengan Kristen.
\end{abstract}

Kata kunci : kemunduran, keruntuhan, daulah Bani Umawiyyah, Damaskus, Spanyol 


\section{PENDAHULUAN}

Nama Dinasti Umawiyah dinisbatkan kepada Umawiyah ibn 'Abd Syams ibn 'Abd Manaf, salah seorang pemimpin suku Quraisy pada zaman Jahiliyah. Bani Umawiyah baru masuk Islam setelah Nabi Muhammad berhasil menaklikkan kota Mekkah (Fath Makkah). Sepetinggal Rasulullah, Bani Umawiyah sesungguhnya telah menginginkan jabatan pengganti beliau (khalifah), tetapi mereka belum berani menampakkan cita-citanya itu pada masa Abu Bakar dan Umar. Baru setelah Umar meninggal. Sebagai penggantinya diserahkan kepada hasil Musyawarah enam orang sahabat, Bani Umawiyah menyokong pencalonan 'Utsman secara terang-terangan, hingga akhirnya 'utsman terpilih. Sejak saat itu mulailah Bani Umawiyah meletakkan dasar-dasar untuk menegakkan khilafah Umawiyah. Pada masa pemerintahan Utsman inilah Umawiyah mencurahkan segala tenaganya untuk memperkuat dirinya dan menyapkan daerah Syam sebagai pusat kekuasaannya di kemudian hari. (Choirul Rofiq, 2009:115)

Umawiyah yang dimaksudkan dalam tulisan ini adalah sebuah dinasti yang didirikan oleh keturunan Umayah atas rintisan Muawiyah (661-680), yang berpusat di Damaskus. ila berbeda dengan Umawiyah Barat yang berkedudukan di Andalusia. Daulah Umawiyah Timur merupakan fase ketiga kekuasaan Islam yang berlangsung selama kurang satu abad (661750 M). Fase ini bukan saja menunjukkan perubahan sistem kekuasaan Islam dari masa sebelumnnya (masa Nabi dan Khulafaurrasyidin), melainkan juga perubahan-perubahan lain dibidang sosial dan peradaban. Ciri menonjol yang ditampilkan dinasti ini, antara lain pemindahan ibukota kekuasaan Islam dari Madinah ke Damaskus; kepemimpinan dikuasai militer Arab dari lapisan bangsawan; dan ekspansi kekuasaan Islam yang lebih meluas yaitu pada masa kekuasaan Islam terbentang sejak dari Spanyol, Afrika Utara, Timur Tengah, sampai ke perbatasan Tiongkok. Dengan demikian, selama periode ini telah berlangsung langkah-langkah baru untuk merekontruksi otoritas dan seklasigus kekuasaan khilafah, dan menerapkan faham golongan bersama dengan elite pemerintah. Kekuasaan Arab menjadi sentralisasi Monarkis.

Dinasti Umawiyah dalam keberhasilannya melakukan ekspansi kekuasaan Islam jauh lebih besar daripada Imperium Roma pada puncak kebesarannya. Keberhasilan ini diikuti pula oleh keberhasilan perjuangan bagi penyebaran syariat Islam, baik dalam bidang keagamaan maupun dalam bidang politik dan ekonomi . dengan begitu, Umawiyah Timur berhasil pula mengembangkan aspek-aspek peradapan Islam yang sangat besar konstribusinya bagi islam pada masa selanjutnya. (Siti Maryam, dkk, 2004 :67)

Dinasti Umawiyah berkuasa selama 89 tahun, yakni dari $661 \mathrm{M} / 41 \mathrm{H}$ sampai dengan 750 M/132 Hselama kurun waktu tersebut, terdapat 14 orang khalifah yang pernah memerintah (Ajid Thoror, $2004:$ 35)

Sepeninggal Hisyam bin Abd al-Malik, khalifah-khalifah Bani Umawiyah yang tampil bukan hanya lemah tetapi juga bermoral buruk. Hal ini makin memperkuat golongan oposisi. Akhirnya pada tahun $750 \mathrm{M}$, daulat Umayyah digulingkan Bani Abbas yang bersekutu dengan Abu Muslim al-Khurasani. Marwan bin 
Muhammad, khalifah terakhir Bani Umawiyah, melarikan diri ke Mesir, di tangkap dan dibunuh di sana (Badri Yatim, 1996: 48)

Ketika Daulah Bani Umayyah Damaskus runtuh pada tahun $132 / 750$, andalusia menjadi salah satupropinsi dari daulah Bani Abbas samapi Abd al-Rahman ibn Mu'awiyah, cucu khalifah Umawiyah kesepuluh Hisyam ibn Abd al-Malik, memproklamasikan propinsi sebagai Negara yang berdiri sendiri pada tahun 138/756. Sejak proklamasi itu andalusia memasuki babak baru sebagai sebuah negara berdaulat di bawah kekuasaan Bani Umawiyah II yang beribukota di Cardova sampai tahun 422/1031. (siti Maryam, dkk, $2004: 81$ )

Dari berbagia kemajuan yang dicapai daulah bani Umawiyah Timur (Damaskus) dan Umawiyah Barat (Spanyol), Pada akhirnya tidak mampu membuat daulah tersebut langgeng bahkan akhirnya mengalami kemunduran dan keruntuhan.

\section{PEMBAHASAN}

\section{Berdirinya Daulah Bani Umawiyah}

Setelah Ustman ibn Affan wafat, masyarakat beramai-ramai membaiat ali ibn Abi Thalib sebagai khalifah. Ali memerintah hanya enam tahun. Selama masa pemerintahannya, ia menghadapi beberapa pergolakan. Tidak ada masa seditpun dalam pmerintahannya yang dapat dikatakan stabil. Setelah menduduki jabatan khalifah, Ali memecat para gubernur yang diangkat oleh Usman, dia yakin bahwa pemeberontakan-pemberontakan terjadi karena ketelodoran mereka. Dia juga menarik kembali tanah yang dihadiahkan usman kepada penduduk dengan menyerahkan hasil pendapatannya kepada Negara, dan memakai kembali Sistem distribusi pajak tahunan di antara orang-orang Islam sebagaimana pernah diterapkan Umar.

Tidak lama setelah itu, Ali ibn Abi Thalib menghadapi pemberontakan Thalhah, Zubair dan Aisyah. Alasan mereka, Ali tidak mau menghukum para pembunuh usman, dan mereka menuntut terhadap darah Usman yang telah ditumpahkan secara zalim. Ali sebenarnya ingin menghindari perang. Dia mengirim surat kepada Thalhah dan Zubair agar keduanya mau berunding untuk menyelesaikan perkara itu secara damai. Namun ajakan tersebut ditolak. Akhirnya pertempuran yang dasyat pun berkobar. Perang ini dikenal dengan nama "Perang Jamal (Unta) karena Aisyah dalam pertempuran itu menunggang unta. Ali berhasil mengalahkan lawannya. Zubair dan Thalhah terbunuh ketika hendak melarikan diri, sedangkan Aisyah ditahan dan dikirim kembali ke Madinah.

Kedudukan Ali sebagai khalifah kemudian dijabat oleh anaknnya Hasan selama beberapa bulan. Namun, karena Hasan ternyata lemah, sementara Mu'awiyah semakin kuat maka Hasan membuat perjanjian damai. Perjanjian ini dapat mempersatukan umat Islam kemali dalam satu kepemimpinan politik, dibawah Mu'awiyah ibn Abi Sufyan. Di sisi lain, perjanjian itu juga menyebabkan Muawiyah menjadi penguasa absolut dalam Islam. Tahun $41 \mathrm{H}(661 \mathrm{M})$, tahun persatuan itu, dikenal dalam sejarah sebagai tahun Jama'ah ('am jama'ah). Dengan demikian berakhirlah apa yang disebut dengan masa Khulafa'ur Rasyiddin, dan dimulailah kekuasaan Bani Umawiyah dalam sejar politik Islam (Badri Yatim, $1996: 41$ ). 
Perpindahan kekuasaan kepada Muawiyah mengakhiri bentuk pemerintahan demokrasi. Kekhalifahan menjadi semacam monarchy heridetis (kerajaan turun-temurun), diperoleh dengan pedang, diplomasi dan tipu daya,tidak degan pemilihan atau suara kebanyakan. (Hassan Ibrahim Hassan, 1989:66)

\section{Perkembangan Peradaban}

Arsitektur. Seni bangunan (arsitektur) pada jaman zaman Umawiyah bertumpu pada bangunan sipil berupa kota-kota dan bangunan sipil berupa masjid-masjid . beberapa kota atau perbaikan kota lama telah dibangun dalam zaman Umawiyah yang diiringi pebangunan berbagai gedung dengan gaya perpaduan Persia, Romawi dan Arab dengan dijiwai semangat Islam. Damaskus yang pada masa sebelum Islam merupakan ibukota kerajaan Romawi timur di Syam adakah kota lama yang dibangun kembali pada masa Umawiyah dan dijadikan Ibukota dinasti ini. Di kota ini didirikan gedung-gedung indah yang bernilai seni dilengkapi jalan-jalandan taman-taman rekreasi yang menakjubkan. Muawiyah membangun Istana Hijau di Miyata pada tahun $704 \mathrm{M}$, istana ini diperbaharui oleh alWalid ibn'Abd al-Malik.

Organisasi Militer. Pada masa Umawiyah organisasi militer terdiri dari angkatan darat (aljund) angkatan laut (al-bahriyah), dan angkatan kepolisian (as-syurthah). Berbeda dengan masa Ustman, bala tentara pada masa ini bukan muncul atas kesadaran sendiri untuk melakukan perjuangan tetapi semacam dipaksakan, sesuai dengan politik Arabisme yang ditempuhnya, angkatan bersenjata terdiri dari orang-orang Arab atau unsur Arab. Setelah wilah kekuasaan meluas sampai ke afrika utara, orang luar pun terutama bangsa barbar turut ambil bagian dalam kemiliteran ini. Pada masa Abd al-Malik ibn Marwan diberlakukan undang-undang wajib militer (nidzam al-tajdid al-ijban). Pada waktu itu aktivitas bala tenatara diperlengkapi dengan kuda, baju besi, pedang dan panah. Angkatan laut yang sesungguhnya telah dirintis oleh Muawiyah sejak masa Umar, tatkala dia akan melakukan penyerangan ke negeri Romawi melalui jalan laut, kemudian pada masa Utsman usahanya itu dilanjutkan dengan pembentukan angkatan musim panas dan musim dingin. Maka semenjak dia resmi menjadi khalifah Umawiyah mulai diusahakan pembuatana kapal-kapal perag guna mengkis serangan armada Byzantium serta keperluan sarana transportasi dalam usaha perluasan kekuasaan Islam kedaerah-daerah lain. Waktu itu armada laut Umawiyah mencapai Rhodes

Reformasi Fiskal. Selama masa pemerintahan mawiyah hampir semua pemilik tanah, baik muslim mupun non muslim, diwajibkan membayar pajak tanah. Sementara itu pajak kepala tidak berlaku bagi pendudk muslim, sehingga banyaknya penduduk yang masuk Islam secara ekonomis merupakan latar belakang berkurangnya penghasilan negara. Namun demikian dengan keberhasilah Umawiyah dalam penaklukan Imperium Sassani (Persia) beserta wilayah kepunyaan imperium Byzantium, sesungguhnya kemakmuran bagi dinasti melimpah-limpah yang megalir je dalam pembendaharaan Negara (Choirul Rofiq, 2009 : 129)

Pengembangan imu-ilmu agama (ulum aldiniyah) sudah mulai dikembangkan karena terasa betapa penduduk-penduduk diluar Jazirah 
Arab sangat memerlukan berbagai penjelasan secara sistematis dan kronologis tentang Islam. IImu-ilmu yang berkembang saat itu antaranya tafsir, hadis, fiqih, ushul fiqih, ilmu kalam dan sirah/tarikh (Ajid Thorir, 2004 :41)

\section{Kemunduran dan Keruntuhan Daulah Bani Umayah Timur (Damaskus)}

Saat Umar II berkuasa dengan kebijakan yang lunak dan bersahabat, baik Khawarij maupun Syi'ah. Tidak ada yang memusuhinya karena kesalehan dan keadilan yang diterapkan Umar II. Kelonggaran bijakan politik Umar II ini dimanfaatkan oleh Bani Abbas, mereka keluar dari bawah tanah dan mudah berkomunikasi sesama anggota gerakan Abbasiyah maupun dengan Syi'ah dan Khawarij yang sejak kelahiran Umayah tidak pernah mengakui sebagai khalifah atau kekuatan politik yang sah dan Islami. Setelah Umar II wafat, mereka segera melancarkan permusuhan dengan dinasti Umayah. Telah disebutkan. Bahwa saat gubernur Khurasan, Nasar ibn Sayyar semasa Marwan II yang memperbaharui ekonomi dengan tujuan untuk membendung gerakan anti umayah melaluinya yang menerapkan Kharaj bagi semua rakyat dengan ukuran yang sama yakni baik muslim Arab, Mawali atau pun Non Muslim, mereka harus bayar pajak bumu yang sama (50\%). Walaupun kebijakan Nasar itu baik, namun waktunya sudah tidak memungkinkan lagi, baikan nasi sudah menjadi bubur. Akhirnya, gerakan Abbasiyah bersama-sama kelompok aliran-aliran yang lain bahu-membahu melawan tentara Umayah di tepi sungai Dzab pada 749 M. Khalifah Marwan II kalah perang dan lari Syam terus ke palestina akhirnya ia ditangkap di mesir dan di bunuh (750 M). (M. Abdul Karim,2009 : 139-141).
Abbasiyyah terus melancarkan serangannya hingga membunuh banyak sekali penduduk Bani Umawiyah. Tidak ada keluarga Bani Umawiyah kecuali dibunuh oleh Abbasiyyin kecuali satu orang saja yang mampu melarikan diri ke Andalusia, yang kemudian mendirikan Negara Umawi di sana (Dr. Yusuf al'lsy, 1998 : 406)

\section{Penaklukan Spanyol}

Tahun 750 bani Abbasiyah meraih tampuk kekuasaan dengan ditandai pembantaian massal terhadap anggota keluarga umayyah. Meski demikian, ada segelintir orang yang luput dari pembantaian, salah satunya adalah Abd alRahman ibn Mu'awiyah, cucu Hisyam, khalifah kesepuluh Damaskus. Kisah tentang selamtnya pemuda berusia dua puluh tahun ini, yang lima tahun menyamar dalam pengembaraan melewati palestina, mesir dan afrika utara, serta beberapa kali Iolos dari ketajaman telik sandi Abbasiyah, telah membentuk salah satu episode paling dramatis dalam sejarah Arab.

Pada pagi hari 14 Mei 756, dua bala tentara yang terlibat dalam pertempuran berhadapan di tepi sungai Guadaquivir. Kendati sebagian besar personil kedua belah pihak menunggang kuda binatang yang masih jarang di Andalusia. Abd alRahman, yang menyadari bahwa sebagian pengikutnya takut ia tinggalkan, meminta agar hewan tunggangnya diganti dengan seekor keledai tua milik Abu al-Shabbah. Pertempuran itu tidak berlangsung lama. Yusuf beserta jenderaljenderal utamanya melarikan diri. Kardova berhasil ditaklukkan dan sebuah amnesty umum diikrarkan. (Philip K. Hitti, 2008 : 644) 


\section{Perkembangan Peradaban}

\section{Kemajuan Intelektual}

Masyarakat Spanyol Islam merupakan masyarakat majemuk yang terdiri dari komunitaskomunitas Arab (utara dan selatan), alMuwalladun (orang-orang yang masuk Islam), Barbar (umat Islam yang berasal dari afrika utara), al-Shaqalibah (penduduk daerah antara Konstantinopel dan Bulgaria yang menjadi tawanan Jerman dan dijual kepada penguasa Islam untuk dijadikan tentara bayaran), Yahudi, Kristen Mujareb yang berbudaya Arab, dan Kristen yang masih menentang kehadiran Islam. Semua komunitas itu, kecuali yang terakhir, memberikan saham intelektual terhadap terbentuknnya lingkungan budaya Andalus yang melahirkan kebangkitan ilmiah, sastra, dan pembangunan fisik di Spanyol.

\section{Filsafat}

Tokoh utama pertama dalam sejarah filsafat Arab-Spanyol adalah Abu Bakr Muhammad ibn al-sayigh yang lebih dikenal dengan ibn Bajjah. Dilahirkan di Saragosa, ia pindah ke Sevilla dan Granada. Meninggal karena keracunan di Fez $1138 \mathrm{M}$ dalam usia yang masih muda. Seberi al-Farabi dan Ibn Sina di Timur, masalah yang dikemukakan bersifat etis dan eskatologis. Magnum opusnya adalah Tadbir alMutawahhid.

Bagian akhir abad ke-12 M menjadi saksi munculnya seorang pengikut Aristoleses yang terbesar di gelanggangan, filsafat dalam Islam, yaitu Ibn Rusyd dari Cardova. la lahir Tahun 1126 $\mathrm{M}$ dan meninggal tahun $1198 \mathrm{M}$. Ciri khasnya adalah kecermatan dalam menafsirkan naskahnaskah Aristoteles dan kehati-hatiannya dalam menggeluti masalah-masalah menahun tentang keserasian filsafat dan agama. Dia juga ahli fiqh dengan karyanya Bidayah al-Mujtahid.

\section{Fikih}

Dalam bidang fikih, Spanyol Islam dikenal sebagai penganut mazhab Maliki. Yang memperkenalkan mazhab ini di sana adalah Ziyad ibn Abd al-Rahman. Perkembangan selanjutnya ditentukan oleh Hisyam ibn Abd al-Rahman. Ahliahli fikih lainnya diantaranya Abu Bakr ibn alQuthiyah, Munzir ibn Sa'id al-Baluthi dan Ibnu Hazm yang terkenal.

\section{Kemegahan Pembangunan Fisik}

Aspek-aspek pembangunan fisik yang menjadi perhatian ummat Islam sangat banyak. Dalam perdagangannya, jalan-jalan dan pasarpasar dibangun. Bidang pertanian demikian juga. Sistem irigasi baru diperkenalkan kepada masyarakat Spanyol yang tidak mengetahui sebelumnnya. Dam-dam, kanal-kanal, saluran sekunder, tersier, dan jembatan-jembatan air didirikan. Tempat-tempat yang tinggi, dengan begitu, juga mendapat jatah air.

\section{Cordova}

Cordova adalah ibukota Spanyol sebelum Islam, yang kemudian di ambil alih oleh Bani Umawiyah. Oleh penguasa muslim, kota ini dibangun dan diperindah. Jembatan besar dibangun di atas sungai yang mengalir di tengah kota. Taman-taman dibangun untuk menghiasi ibukota Spanyol Islam itu. Pohon-pohon dan bunga-bunga diimpor dari timur. Di seputar ibukota berdiri istana-istana yang megah yang semakin mempercantik pemandangan, setiap istana dan taman diberi nama tersendiri dan puncaknya terpancang istana Damsik. 


\section{Granada}

Granada adalah tempat pertahanan terakhir ummat Islam di Spanyol. Disana berkumpul sisasisa kekuatan Arab dan pemikir Islam. Posisi Cardova diambil alih oleh Granada di masa-masa akhir kekuasaan Islam di Spanyol. Arsitekturarsitektur bangunannya terkenal di seluruh Eropa. Istana Al-Hamra yang indah dan megah adalah pusat dan puncak ketinggian arsitektur Spanyol Islam. Istana itu dikelilingi taman-taman yang tidak kalah indahnya.

Kisah tentang kemajuan pembangunan fisik ini masih diperpanjang dengan kota dan istana alZahra, istana al-Gizar, menara Girilda dan lainlain. (Badri Yatim, 2001 :105).

\section{Kemunduran dan Keruntuhan Daulah Bani Umawiyah Barat (Spanyol)}

\section{Ihwal Pemerintahan}

Malapetaka kehancuran mulai melanda istana ketika pemuka-pemuka Bani Umawiyah memecat al-Mu'ayyad dari jabatan khalifah, karena ia bersedia memberikan jabatan tertinggi negara itu kepada al-Nahir II dinilai sepetinggalnya kelak. Mulai saat itu perebutan kursi khalifah sudah tidak bisa dihindari. Para pemuka penduduk Cordova segera meminta Umawiyah ibn Abd al-Rahman agar bersedia menduduki jabatan kahlifah. Akan tetapi, ia tidak sempat menikmati jabatan tertinggi negara itu, karena terpaksa harus bersembunyi untuk menyelamatkandiri dari bahaya yang mengancam dirinya. Dalam waktu itu, Wazir Abu al-Hazm ibn Jahwar memaklumkan penghapusan Khilafah untuk selamanya, karena dianggap tidak ada lagi orang yang layak atas jabatan itu. Di atas puing puing kehancuran daulah Umawiyah Andalusia memasuki babak baru yang dikenal dengan periode Muluk al-Thawaif. (Siti Maryam, dkk, 2004 : 81).

\section{Kerajaan Granada}

Kerajaan granda merupakan pertahan terakhir muslim di Spanyol. Setelah terjadi penaklukkan kota Valencia, Kardoba, Saville dan Murcea oleh penguasa Aragon yang bernama Jayme I, pemerintahan muslim di spanyol tinggal bertahan di propinsi Granada. Bahkan penguasa Granada juga dipaksa membayar sejumlah upeti kepada pemerintahan Catille. Kerajaan Granada ini didirikan oleh ibn al-Ahmar.

Tidak lama kemudian Ferdinand mengeluarkan sebuah dektrit dimana umat Islam harus memilih dua alternatif, bersedia dibaptis sebagai pemeluk Kristen atau keluar dari Spanyol. (Prof. K. Ali, 2003 : 476)

\section{KESIMPULAN DAN SARAN \\ Kesimpulan}

1. Faktor kemunduran hingga menyebabkan keruntuhan daulah bani Umawiyah Timur (Damaskus) sebagai berikut (1). Lemahnya para Khalifah, diantara empat belas khalifah dari dinasti umayyah, hanya beberapa khalifah yang cakap, kuat, dan pandai mengendalikan Negara. Selain Umawiyah, Abd al-Malik, al-Walid I, Sulaiman Umar II, dan Hisyam kesemuanya adalah lemah dan memiliki banyak kekurangan dan kelemahan dalam memimpin Negara yang begitu luas. (2). Munculnya konflik antar golongan. Hal ini seperti golongan Himyar dan Mudhar, yang selalu bermusuhan. Dan para khalifah hidup dalam kemewahan, contoh : Yazid II, yang sangat mencintai seorang penari dan suka minum-minuman keras yang berlebihan. (3). 
Penyebab langsung tergulingnya kekuasaan daulah bani Umawiyah muncul kekuatan baru yang dipelopori oleh keturunan al-Abbas ibn Abd al-Muthalib, gerakan ini didukung oleh bani Hasyim dan golongan Syi'ah, kaum mawali yang merasa dikelasduakan oleh bani Umawiyah.

2. Adapun faktor kemunduran hingga menyebabkan keruntuhan daulah bani Umawiyah Barat (Andalusia), adalah : (1). Tidak jelasnya sistem peralihan kekuasaan. Ketidakjelasan sistem pergantian khalifah ini menyebabkan terjadinya persaingan yang tidak sehat di kalangan anggota keluarga istana. (2) para penguasa lebih mengutamakan membangun kota dan mengembangkan ilmu pengetahuan akibatnya timbul kesulitan ekonomi. (3). Tidak adanya ideologi pemersatu karena adanya perlakuan bani Umawiyah yang diskirimantif terhadap mualaf muwalladun), pada akhirnya melahirkan dinasti-dinasti kecil. (4) terjadinya konflik Islam dengan Kristen disebabkan penaklukan daulah Umawiyah di Andalusia sehingga pihak Kristen melakukan penaklukan kembali. Adapun daerah yang terakhir dikuasai oleh umat Muslim di Spanyol adalah Granada di bawah kekuasaan Abul Hasan. Pada tanggal 3 januari 1492 M, Granada merupakan daerah terakhir dikuasai oleh Kristen dibawah pimpinan Ferdinand.

\section{Saran}

1. Dari faktor kemunduran dan keruntuhan daulah bani Umawiyah Timur (Damaskus) seperti lemahnya para khalifah, munculnya konflik antar golongan, penyebab langsung tergulingnya kekuasaan daulah bani Umawiyah, munculnya kekuatan baru seperti keturunan al-Abbas ibn Abd al-Muthalib maka perlu figur pemimpin yang dapat memberikan contoh tauladan kepada rakyatnya.

2. Dari Faktor kemunduran dan keruntuhan daulah bani Umawiyah Barat (Andalusia) seperti tidak jelasnya sistem peralihan kekuasaan, kesulitan ekonomi, tidak adanya ideologi pemersatu, terjadinya konflik Islam dengan Kristen maka disarankan perlu adanya masa jabatan seorang pemimpin supaya adanya perubahan pemerintahan.

\section{DAFTAR PUSTAKA}

Ali, K, 2003, Sejarah Islam (Tarikh Pramodern), Raja Grafindo Persada, Jakarta

Al 'isy, Yusuf ,2007, dinasti Umawiyah, Pustaka Al-Kautsar, Jakarta Timur

Hassan, Hassan Ibrahim, 1989, sejarah dan kebudayaan Islam, kota Kembang, Yogyakarta

Hitti, Philip. K, 2008, History of the Arabs, Serambi Ilmu Semesta, Jakarta.

Karim, M. Abdul, 2009, sejarah pemikiran peradaban Islam, Pustaka Book Publisher, Yogyakarta.

Maryam, Siti, dkk, 2004, sejarah peradapan Islam : Dari masa Klasik Hingga Modern, LESFI, Yogyakarta

Rofiq, Choirul, 2009, sejarah peradaban islam : dari masa klasik hingga modern, STAIN, Ponorogi Press, Yogyakarta.

Thohir, ajid, 2004, perkembangan peradaban di kawasan Dunia Islam, Raja Grafindo Persada, Jakarta , 2004

Yatim, Badri, 1996, sejarah Peradaban Islam, Raja Grafindo Persada, Jakarta. 